\title{
Impact of endoscopic ultrasound-guided fine needle aspiration of small lymph nodes
}

\author{
Narendra S. Choudhary, Rinkesh Kumar Bansal, Rajesh Puri, Vijay Bodh, Gaurav Kumar Patil, \\ Mukesh Nasa, Rajiv Ranjan Singh, Haimanti Sarin ${ }^{1}$, Mridula Guleria ${ }^{1}$, Randhir Sud
}

Institute of Digestive and Hepatobiliary Sciences, 'Department of Cytopathology, Medanta - The Medicity, Gurgaon, Haryana, India

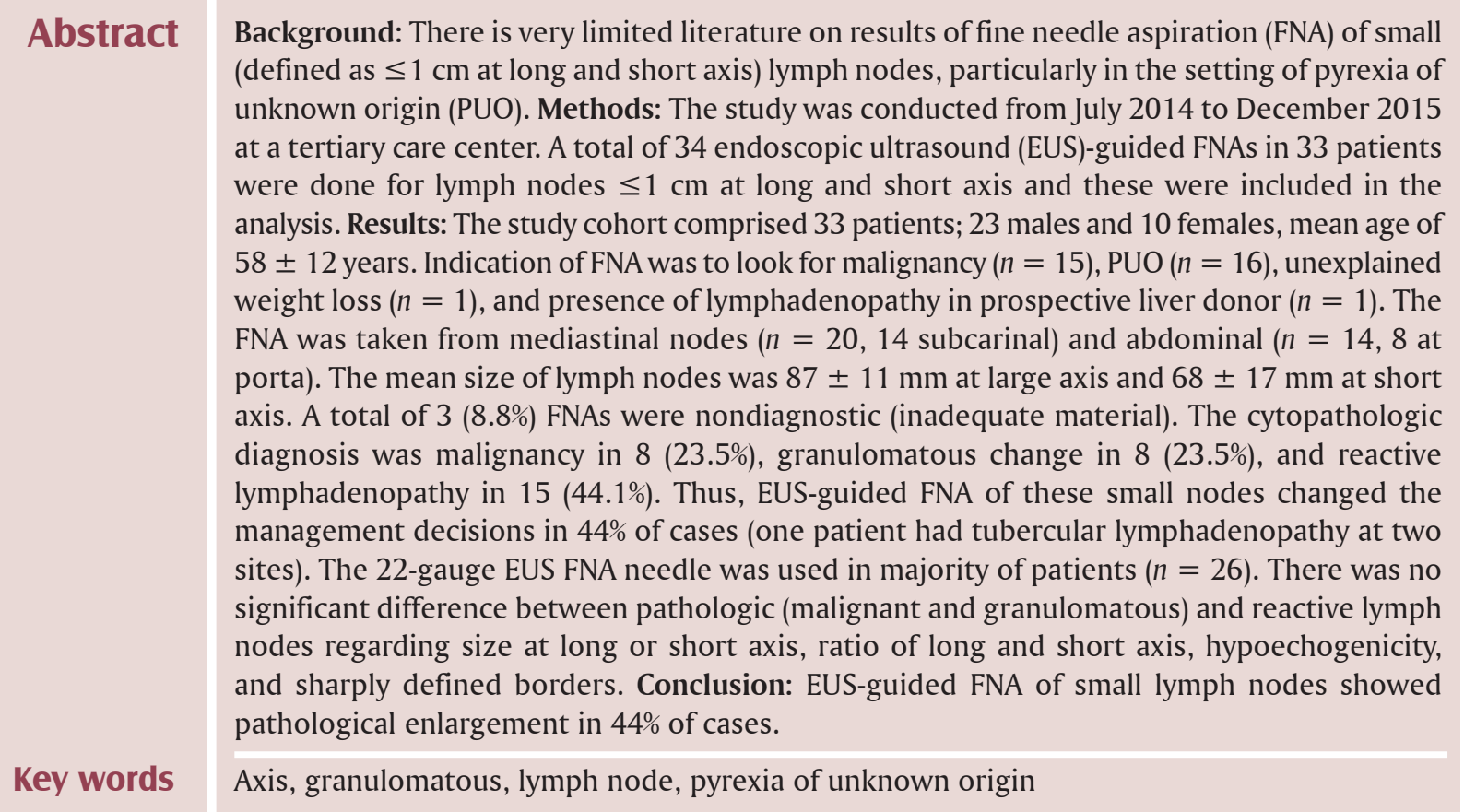

\section{Introduction}

Small (or subcentimetric) lymph nodes are defined as short axis diameter $<1 \mathrm{~cm}$ (long axis may be $>1 \mathrm{~cm}$ in size). Often these lymph nodes are detected by current refined diagnostic modalities (computed tomography or magnetic resonance

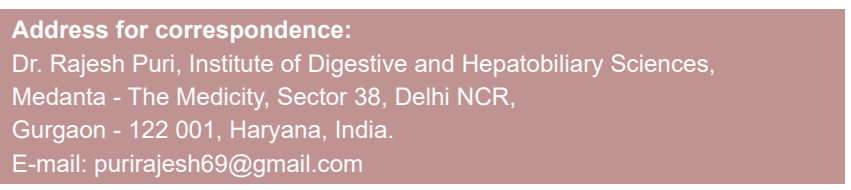

\begin{tabular}{|l|c|}
\hline \multicolumn{2}{|c|}{ Access this article online } \\
\hline \multirow{2}{*}{$\begin{array}{l}\text { Website: } \\
\text { www.jdeonline.in }\end{array}$} & Quick Response Code \\
\hline $\begin{array}{l}\text { DOI: } \\
\text { 10.4103/0976-5042.189137 }\end{array}$ & \\
\hline
\end{tabular}

imaging) done for some other purpose. Furthermore, multiple postmortem studies in patients with no chest infection or malignancy have shown that presence of these nodes is common..$^{[1-3]}$ There is very limited literature regarding lymph nodes with both long and short axis $\leq 1 \mathrm{~cm}$ in size, we have defined these nodes as small nodes for purpose of the present study. These lymph nodes are difficult to fine needle aspiration (FNA) due to small size and location. Endoscopic ultrasound (EUS)-guided FNA offers real-time vision and it has been proved to be very safe from mediastinum where vascular

This is an open access article distributed under the terms of the Creative Commons Attribution-NonCommercial-ShareAlike 3.0 License, which allows others to remix, tweak, and build upon the work non-commercially, as long as the author is credited and the new creations are licensed under the identical terms.

For reprints contact: reprints@medknow.com

How to cite this article: Choudhary NS, Bansal RK, Puri R, Bodh V, Patil GK, Nasa M, et al. Impact of endoscopic ultrasound-guided fine needle aspiration of small lymph nodes. J Dig Endosc 2016;7:51-4. 
structures are abundant. ${ }^{[4]}$ There is a lack of knowledge about nature of these small lymph nodes $(\leq 1 \mathrm{~cm}$ at long and short axis), and scarce data are available in the setting of pyrexia of unknown origin (PUO). In the present study, we describe our experience of EUS-guided FNA of small mediastinal or abdominal lymph nodes in the setting of PUO or nonlung malignancy.

\section{Methods}

The study was conducted from January 2014 to December 2015 at a tertiary care center in North India (Delhi NCR). All the patients who underwent EUS-guided FNA of small lymph nodes (defined as $\leq 1 \mathrm{~cm}$ at both long and short axis) were included in the analysis. The study was conducted prospectively after clearance from the Institute's Review Board/Ethical Committee. A total of 476 EUS-guided lymph node FNA were done at our center in defined time period, out of which, $34(7.1 \%)$ were done for small lymph nodes. EUS-guided FNA was done for those nodes which were not easily accessible by percutaneous ultrasound and when diagnosis could not be achieved by other easier/noninvasive methods. All the procedures were carried out in conscious sedation (midazolam). EUS-guided FNA was done using GF-UCT140 linear echoendoscope (EUS scope, Olympus, Tokyo, Japan). The primary objective of the study was to look for safety and diagnostic accuracy of EUS-guided FNA of small lymph nodes. Following data were recorded for each patient; age, sex, indication for procedure (PUO vs. malignancy), site of lymph node, echo features of lymph node, size at short and long axis, type and number of needle passes, number of slides, result of FNA, and any procedural complications. In the presence of multiple lymph nodes, node with larger size/having sharply demarcated borders/hypoechoic in nature following features was preferred for FNA. A lymph node was considered reactive when FNA showed lymphoid cells in different stages of activation in the presence of adequate cellularity and absence of granulomas/necrosis/malignant cells.

\section{Endoscopic ultrasound fine needle aspiration procedure}

A lymph node was selected based on above-mentioned criteria for FNA if feasible (avoidance of vascular structures and vital organs). A linear array echoendoscope was directly inserted into the esophagus. EUS FNA needle with stylet was introduced in working channel; Doppler was used to avoid any vascular structures in needle path. The stylet was withdrawn slightly before puncture; it was reintroduced fully after puncture of lymph node to displace any material in needle (from gastrointestinal wall). After that stylet was completely withdrawn; 10-20 to and fro movements of needle were done within lymph node. The material inside needle was pushed on slides bit by bit with help of stylet. One or two slides from each pass were immediately fixed in absolute alcohol and rest were air dried. The slides were stained with Papanicolaou, Giemsa stain, and Ziehl-Neelsen stain (wherever required).
The type of needle and method of FNA (suction, no suction, or capillary) and number of needle passes (as we do not have on-site cytopathologist facility) were operator's dependent. A different needle was used for different lymph node if needed.

\section{Statistical analysis}

The data are shown as number, percentage, and mean (standard deviation). Two groups were compared with Student's $t$-test or Fisher's exact test (nominal data). A two-tailed $P<0.05$ was considered statistically significant. All statistical analysis was performed with SPSS, version 16 (SPSS, SPSS Inc., Chicago, IL, USA).

\section{Results}

The study cohort comprised 33 patients; 23 males and 10 females. The mean age of study cohort was $58 \pm 12$ years. A total of 34 lymph nodes FNA were done. Indication of FNA was to look for malignancy $(n=15)$, PUO $(n=16)$, presence of lymphadenopathy in unexplained weight loss $(n=1)$, and prospective liver donor $(n=1)$. The primary in cases of malignancy included hepatocellular carcinoma in 10 patients and FNA was done before liver transplantation to rule out metastasis, other sites of primary included carcinoma of cholangiocarcinoma $(n=4)$ and esophagus $(n=1)$. The FNA was taken from mediastinal nodes ( $n=20,14$ subcarinal) and abdominal ( $n=14,8$ at porta). The prospective liver donor was asymptomatic, imaging showed small lymph nodes at porta and mediastinum, and she underwent FNA from both of these sites. The mean size of lymph nodes was $87 \pm 11 \mathrm{~mm}$ at long axis and $68 \pm 17 \mathrm{~mm}$ at short axis. The mean ratio of long to short axis was $1.2 \pm 0.29$. A total of $3(8.8 \%)$ FNAs were nondiagnostic (inadequate material). None of the patients had any complication related to anesthesia or FNA procedure. The cytopathologic diagnosis was malignancy in $8(23.5 \%)$, granulomatous lymphadenopathy in $8(23.5 \%)$, and reactive lymphadenopathy in 15 (44.1\%). The prospective donor had presence of granulomas in both aortopulmonary and porta lymph nodes; AFB stain was positive from AP window lymph node. The patient who presented with weight loss had azygoesophageal lymph node and FNA showed granulomas and necrosis. When patients with nondiagnostic FNA (inadequate material) were compared to patients with diagnostic FNA, there was no significant difference regarding long axis and short axis diameter. The 22 -gauge EUS FNA needle was used in majority of patients $(n=26)$ and a 25-gauge needle was used in rest of the patients. Out of eight granulomatous lymph nodes, five also showed the presence of necrosis, one showed the presence of calcification, and this node was positive for AFB stain. Only one of these granulomatous lymph nodes showed the presence of patchy hypoechoic area within. A positive diagnosis (pathologic versus reactive enlargement) could be made in $18 / 20$ of mediastinal and $13 / 14$ of abdominal lymph nodes $(P=0.83)$. The sex ratio was equal in pathologic versus reactive node groups (10 males and 5 females in each group, 3 males had 
inadequate material for diagnosis). Thus, EUS-guided of these small nodes changed the management decisions in $44 \%$ of cases ( $47 \%$ of FNAs, one patient had FNA from 2 sites). Representative images with cytopathological diagnosis are shown in Figures 1-3.

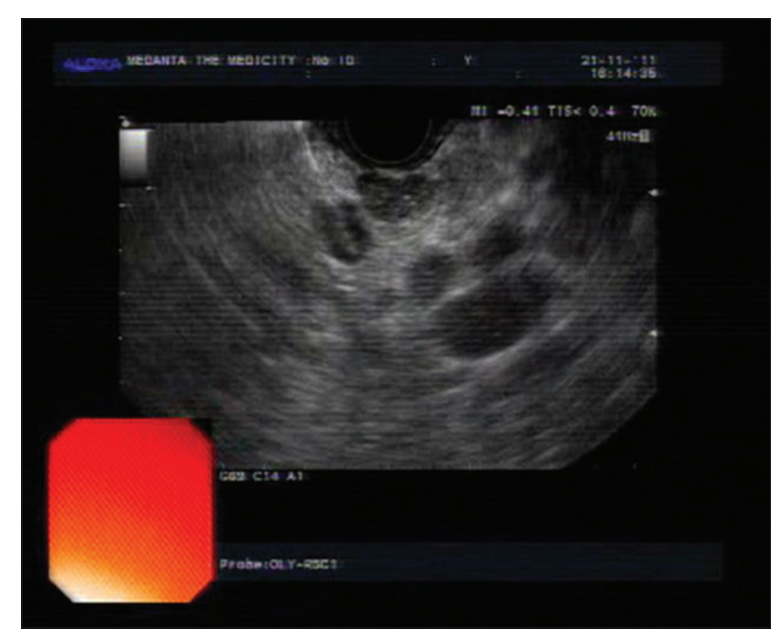

Figure 1: Malignant lymph node at porta

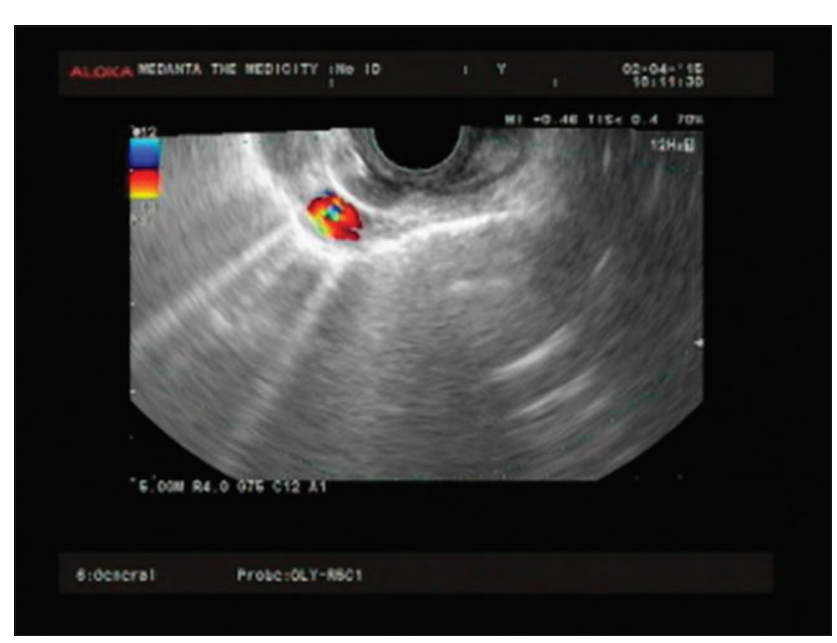

Figure 2: Granulomatous lymph node near azygos vein

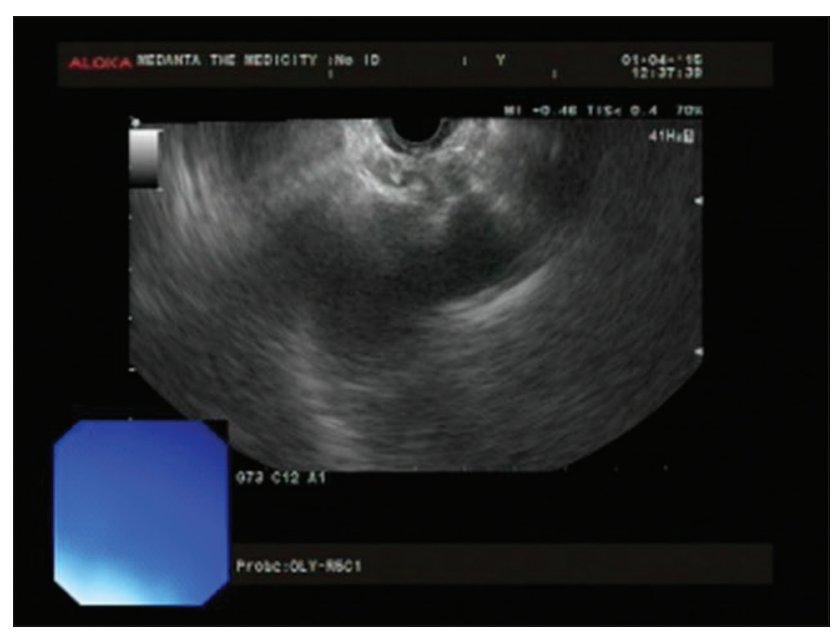

Figure 3: Granulomatous lymph node in AP window

\section{Discussion}

There is no uniform definition of small versus very small lymph nodes, for the purpose of the present study, we defined small lymph nodes as $\leq 1 \mathrm{~cm}$ at both long and short axis. Subcentimetric (small) lymph nodes are defined as $<1 \mathrm{~cm}$ at short axis, and there is a lack of literature on lymph nodes $\leq 1 \mathrm{~cm}$ at both long and short axis. These sub-centimetric lymph nodes ( $<1 \mathrm{~cm}$ at short axis) were considered as benign based on several studies. ${ }^{[1-3]}$ With evolution of EUS-guided FNA, mediastinal FNA can be done very safely, and it has shown to be accurate. ${ }^{[4]}$ Few studies have shown that some of small nodes may be malignant; however, data are limited to lung carcinoma. ${ }^{[5-7]}$ There is a lack of literature on FNA results of small lymph nodes ( $\leq 1 \mathrm{~cm}$ at both long and short axis) in other indications, particularly PUO. The traditional criteria of malignant node include size $>1 \mathrm{~cm}$, round shape, sharply defined border, and homogeneous/hypoechoic echo pattern. ${ }^{[8]}$ Recently, Jamil et al. ${ }^{[9]}$ compared 68 benign lymph nodes with 94 pathological lymph nodes. The authors showed that various echo features including echogenicity, margins, and shape were not significantly different between these groups, only size was significantly different. Tuberculosis is the most common cause of PUO in India, we recently described our experience of 53 tubercular nodes (accepted for publication in Indian Journal of Gastroenterology), the morphological features of these nods included hypoechoic echotexture (94.5\%), patchy anechoic/hypoechoic areas $(30.2 \%)$, calcification $(24.5 \%)$, sharply demarcated borders (34.5\%), pus-like material on aspirate (18.2\%), and conglomeration of lymph nodes $(10.9 \%)$. The tubercular lymph nodes have a size of $2.4 \pm 1.1 \mathrm{~cm}$ and $1.5 \pm 0.7 \mathrm{~cm}$ at short axis. As shown in Table 1, EUS morphological criteria are not different between pathologically enlarged and reactive nodes in small nodes. Some of the features of tubercular nodes describe above such as calcification (present in only one node), patchy hypoechoic areas were also not present in small nodes. We have a major difference with other published studies as a significant proportion of sample size had PUO as indication of FNA. In these patients, granulomatous pathology was predominant cause of pathological lymph node enlargement. Our findings are similar to two other studies from India in patients with mediastinal lymphadenopathy that suggested tuberculosis in 32 out of 60 patients and 22 out of

$\overline{\text { Table 1: Comparison of pathologic and reactive lymph nodes }}$ ( $n=31)$

\begin{tabular}{lccc}
\hline Parameter & $\begin{array}{c}\text { Malignant/ } \\
\text { granulomatous } \\
\text { change }(n=16)\end{array}$ & $\begin{array}{c}\text { Reactive } \\
\text { lymph nodes } \\
(n=15)\end{array}$ & $P$ \\
\hline Age (years) & $55.2 \pm 13.6$ & $60.3 \pm 11.3$ & 0.27 \\
Long axis (mm) & $89 \pm 9$ & $85 \pm 13$ & 0.36 \\
Short axis (mm) & $72 \pm 19$ & $65 \pm 16$ & 0.28 \\
Long and short axis ratio & $1.19 \pm 0.27$ & $1.17 \pm 0.35$ & 0.82 \\
Hypoechogenicity & 9 & 7 & 0.72 \\
Well-defined borders & 8 & 5 & 0.47 \\
Number of slides & $10.1 \pm 4.3$ & $12.8 \pm 3.8$ & 0.09 \\
Number of passes & $2.07 \pm 0.59$ & $2.5 \pm 0.94$ & 0.14 \\
\hline
\end{tabular}


42 patients. ${ }^{[10,11]}$ We did not encounter any complication during this study. A meta-analysis of 32 studies of mediastinal lymph node FNA by Puli et al. showed complication rate of $0-2.3 \%$ across studies. ${ }^{[4]}$ Our study has limitations in the form of no follow-up of patients with granulomatous change as PUO patients are referred from other hospitals or other departments for purpose of EUS-guided FNA. We do not want to suggest that all lymph nodes seen in mediastinum or abdomen should be sampled in asymptomatic patients (as they are present in normal individuals also). We suggest that small lymph nodes should be sampled when it is indicated like in our series (for PUO or to confirm malignant lymphadenopathy and thus avoiding futile surgeries). The unnecessary (futile) surgery could be avoided in almost half of patients with malignancy in current series. Although sample size is small in the present study, these truly small ( $\leq 1 \mathrm{~cm}$ at both long and short axis) nodes are uncommon at presentation to clinicians as reflected by total number of FNAs done by us in defined study period. In conclusion, we shown that small lymph nodes are pathologically enlarged in significant percentage of patients and they should be sampled whenever clinically indicated. Pathological features cannot differentiate between reactive and pathological small lymph nodes.

\section{Financial support and sponsorship}

Nil.

\section{Conflicts of interest}

There are no conflicts of interest.

\section{References}

1. Kiyono K, Sone S, Sakai F, Imai Y, Watanabe T, Izuno I, et al. The number and size of normal mediastinal lymph nodes: A postmortem study. AJR Am J Roentgenol 1988;150:771-6.

2. Ziyade S, Pinarbasili NB, Ziyade N, Akdemir OC, Sahin F, Soysal Ö, et al. Determination of standard number, size and weight of mediastinal lymph nodes in postmortem examinations: Reflection on lung cancer surgery. J Cardiothorac Surg 2013;8:94.

3. Glazer GM, Gross BH, Quint LE, Francis IR, Bookstein FL, Orringer MB. Normal mediastinal lymph nodes: Number and size according to American Thoracic Society mapping. AJR Am J Roentgenol 1985;144:261-5.

4. Puli SR, Batapati Krishna Reddy J, Bechtold ML, Ibdah JA, Antillon D, Singh S, et al. Endoscopic ultrasound: It's accuracy in evaluating mediastinal lymphadenopathy? A meta-analysis and systematic review. World J Gastroenterol 2008;14:3028-37.

5. Arita T, Kuramitsu T, Kawamura M, Matsumoto T, Matsunaga N, Sugi K, et al. Bronchogenic carcinoma: Incidence of metastases to normal sized lymph nodes. Thorax 1995;50:1267-9.

6. Izbicki JR, Thetter O, Karg O, Kreusser T, Passlick B, Trupka A, et al. Accuracy of computed tomographic scan and surgical assessment for staging of bronchial carcinoma. A prospective study. J Thorac Cardiovasc Surg 1992;104:413-20.

7. Kondo D, Imaizumi M, Abe T, Naruke T, Suemasu K. Endoscopic ultrasound examination for mediastinal lymph node metastases of lung cancer. Chest 1990;98:586-93.

8. Catalano MF, Nayar R, Gress F, Scheiman J, Wassef W, Rosenblatt ML, et al. EUS-guided fine needle aspiration in mediastinal lymphadenopathy of unknown etiology. Gastrointest Endosc 2002;55:863-9.

9. Jamil LH, Kashani A, Scimeca D, Ghabril M, Gross SA, Gill KR, et al. Can endoscopic ultrasound distinguish between mediastinal benign lymph nodes and those involved by sarcoidosis, lymphoma, or metastasis? Dig Dis Sci 2014;59:2191-8.

10. Puri R, Vilmann P, Sud R, Kumar M, Taneja S, Verma K, et al. Endoscopic ultrasound-guided fine-needle aspiration cytology in the evaluation of suspected tuberculosis in patients with isolated mediastinal lymphadenopathy. Endoscopy 2010;42:462-7.

11. Rana SS, Bhasin DK, Srinivasan R, Singh K. Endoscopic ultrasound (EUS) features of mediastinal tubercular lymphadenopathy. Hepatogastroenterology 2011;58:819-23. 